\title{
SALINIDADE E TEMPERATURA NA GERMINAÇÃO E VIGOR DE SEMENTES DE MUTAMBO (Guazuma ulmifolia LAM.) (STERCULIACEAE) ${ }^{1}$
}

\author{
Roseli Betoni², Silvana de Paula Quintao Scalon ${ }^{3}$ e Rosilda Mara Mussury ${ }^{4}$
}

\begin{abstract}
RESUMO - Este trabalho teve como objetivo avaliar a germinação e o vigor de sementes e plântulas de mutambo em resposta à salinidade e a diferentes temperaturas. O experimento foi realizado em laboratório onde as sementes foram colocadas em placas de Petri com soluções salinas de $\mathrm{KCl}, \mathrm{NaCl}$ e $\mathrm{CaCl}_{2}$ nos potenciais osmóticos de 0,0 (testemunha); -0,4; -0,8; -1,2; -1,6; -2,0 MPa acrescidas (CE) ou não (SE) de espermidina (100ppm). As sementes foram incubadas em BOD, nas temperaturas de $15,20,30$ e $35^{\circ} \mathrm{C}$. Para cada sal, o delineamento experimental foi inteiramente casualizado, com três repetições de 20 sementes. Não houve germinação na temperatura de $15^{\circ} \mathrm{C}$. Para os três sais , os valores para porcentagem de germinação foram maiores a $30^{\circ} \mathrm{C}$. Os valores do índice de velocidade de germinação (IVG) diminuíram com a redução dos potenciais osmóticos (PO). O IVG e a massa fresca (MF) apresentaram maiores médias na temperatura de $30^{\circ} \mathrm{C}$. A relação raiz/ parte aérea foi significativamente maior na temperatura de $20^{\circ} \mathrm{C}$, não diferindo significativamente entre CE e SE. Os valores de MF de sementes CE reduziram-se com a diminuição dos PO. Os maiores valores de massa seca (MS) ocorreram a 30 e $35^{\circ} \mathrm{C}$ nos tratamentos com $\mathrm{KCl}$ e $\mathrm{NaCl}$ e a $30^{\circ} \mathrm{C}$ com o $\mathrm{CaCl}_{2}$ Não houve diferença significativa na interação entre sal e potencial osmótico para a massa seca. Nas condições controladas deste estudo, Guazuma ulmifolia apresentou germinação e crescimento de plântula em ambiente com salinidade de -2,0MPa e temperatura em torno de $30^{\circ} \mathrm{C}$, não apresentando limite de tolerância até essa concentração em nenhum dos sais avaliados.
\end{abstract}

Palavras-chave: Árvore nativa, Espermidina e Estresse.

\section{SALINITY AND TEMPERATURE IN THE GERMINATION AND VIGOR OF GUazuma ulmifolia LAM. (STERCULIACEAE) SEEDS}

\begin{abstract}
The objective of this work was to evaluate the germination and vigor of seeds and seedlings of Guazuma ulmifolia in response to salinity and to different temperatures. The experiment was carried in laboratory where the seeds were placed in Petri plates with saline solutions of $\mathrm{KCl}, \mathrm{NaCl}$ and $\mathrm{CaCl}_{2}$ in the osmotic potentials of 0.0 (control); -0.4; -0.8; -1.2; -1.6; -2.0 MPa added(CE) or not (SE) with spermidine (100ppm). The seeds were incubated in BOD at the temperatures of $15,20,30$ and $35^{\circ} \mathrm{C}$. For each salt, the experimental design was completely randomized with 3 replicates of 20 seeds. There was no germination at $15^{\circ} \mathrm{C}$. For the three salts, values for germination percentage were the greatest at $30^{\circ} \mathrm{C}$. The values of the germination speed index (GSI) were reduced with the reduction of osmotic potentials (PO). The IVG and fresh mass (FM) presented the greatest means at $30^{\circ} \mathrm{C}$. The relationship root/aerial part was significantly higher at $20^{\circ} \mathrm{C}$, which did not significantly differed between CE and SE. The values of FM of CE seeds reduced with the reduction of the $P O$. The greatest values of dry mass $(D M)$ occurred at 30 and $35^{\circ} \mathrm{C}$ in the treatments with $\mathrm{KCl}$ and $\mathrm{NaCl}$ and at $30^{\circ} \mathrm{C}$ for $\mathrm{CaCl}_{2}$. There was no significant difference in the interaction between salt and osmotic potentials for dry mass. In the controlled conditions of the present study, Guazuma ulmifolia presented germination and seedling growth in -2.0MPa salinized environment and temperature around $30^{\circ} \mathrm{C}$, not showing limit of tolerance up to this concentration in none of the evaluated salts.
\end{abstract}

Keywords: Native trees, Spermidine and Stress.

\footnotetext{
${ }^{1}$ Recebido em 20.03.2009 e aceito para publicação em 18.04.2011.

${ }^{2}$ Instituto Federal do Triângulo Mineiro, IFTM, Brasil. E-mail: <roselibetoni@yahoo.com.br>.

${ }^{3}$ Universidade Federal da Grande Dourados, UFGD, Brasil. E-mail: < silvanascalon@ufgd.edu.br>e < maramussury@ufgd.edu.br>.
} 


\section{INTRODUÇÃO}

Devido ao processo intenso e contínuo de exploração, a atividade antrópica vem influenciando o meio ambiente e causando impactos como a devastação de matas nativas, que reduzem a ocorrência de várias espécies com potencial para múltiplos usos.

Um exemplo dessa ação antrópica é a prática de adicionar nutrientes ao solo, que, em algumas situações onde não se faz o manejo integrado da adubação e da irrigação para assegurar a sustentabilidade da agricultura, pode levar a aumentos na concentração de sais no solo, o que inviabiliza o cultivo da maioria das plantas naquele local. Frequentemente, os problemas de salinidade na agricultura também podem ser devidos à qualidade da água usada na irrigação, à menor eficiência de lixiviação dos sais e da drenagem do solo (SILVA et al., 2009).

Uma vez que o aumento da salinidade dos solos está associado à redução dos seus potenciais ao ponto de limitar a germinação de sementes, tornam-se relevantes os estudos de germinação e desenvolvimento inicial das plântulas de espécies nativas, sobretudo aquelas comumente utilizadas em projetos de reposição de cobertura vegetal em áreas degradadas.

A resistência à salinidade é descrita como a habilidade de evitar que excessiva quantidade de sal proveniente do substrato alcance o protoplasma e também de tolerar os efeitos tóxicos e osmóticos associados ao aumento da concentração de sais (LARCHER, 2000). O aumento da concentração de compostos como prolina, polióis e açúcares, que ocorrem quando há estresse hídrico ou salino, proporciona redução na perda de atividade enzimática ou da integridade da membrana, levando à manutenção do potencial osmótico da célula compatível com a manutenção da estabilidade de algumas macromoléculas (FREIRE, 2000).

As poliaminas putrescina (Put), espermidina (Spd) e espermina (Spm), incluídas entre os fitorreguladores, além de interagir com as membranas celulares, eliminar radicais livres e alterar a expressão gênica, são importantes moduladores de processos biológicos como divisão celular, repostas ao estresse e desenvolvimento (KOETJE et al., 1993).

Um dos métodos mais defendidos para se determinar o limite de tolerância das plantas aos sais é a observação da porcentagem de germinação das sementes, parâmetro que pode ser utilizado como um indicador da sensibilidade ou não das plantas à salinidade em estádios subsequentes do crescimento e desenvolvimento (LARCHER, 2000).

Na revisão de literatura realizada não foram encontrados trabalhos envolvendo a espécie Guazuma ulmifolia nem mesmo outras pertencentes à família Sterculiaceae submetidas a estresse salino e nem mesmo sobre a interação temperatura e salinidade do ambiente. No entanto, por ser uma espécie arbórea pertencente aos estágios iniciais de sucessão secundária, sendo classificada por Ferretti et al. (1995) como secundária inicial, apresenta grande potencial para a revegetação de áreas degradadas (LORENZI, 2002). Além disso, vem sendo utilizada com o objetivo de restauração do solo, quebra vento e revegetação em dunas degradas por mineração (ROSADO et al., 2008). Dessa forma, trabalhos que investiguem o desenvolvimento inicial dessa espécie e suas respostas fisiológicas, também em condições de salinidade, é um passo importante para auxiliar em programas de recuperação de áreas degradadas pela ação antrópica.

Entretanto, para compreender como ocorre a regeneração natural ou de que forma o homem pode fazer a reposição da cobertura vegetal de uma área degradada, é necessário o conhecimento da ecofisiologia destas espécies. De acordo com Kageyama et al. (2003), a reposição de cobertura vegetal pode ter um papel importante na conservação da biodiversidade desde que haja um trabalho criterioso no estabelecimento de populações representativas de espécies nativas do local a ser restaurado, para isso é necessário ainda determinar, dentre outros fatores, a temperatura adequada para a germinação de sementes.

Diante do exposto, o objetivo deste trabalho foi avaliar a germinação e o vigor de sementes e plântulas de mutambo em resposta à salinidade e a diferentes temperaturas.

\section{MATERIAL E MÉTODOS}

Os frutos de mutambo foram coletados após a queda espontânea no mês de junho de 2007, no município de Dourados-MS, de diversas matrizes no Campus II da UFGD-MS, localizada a 22¹3'16"S, longitude 54 ${ }^{\circ} 17^{\prime} 01^{\prime \prime}$ W e altitude de $430 \mathrm{~m}$., e armazenados em sacos plásticos pretos. Os frutos foram primeiramente selecionados, retirando os que apresentavam deformação e sinais de ataque de insetos. Em seguida, foram quebrados 
para extração das sementes, que foram retiradas manualmente das cápsulas e descartadas aquelas que apresentavam sinais de predação.

Os experimentos foram conduzidos no Laboratório de Sementes da Faculdade de Ciências Agrárias da Universidade Federal da Grande Dourados (UFGD), durante o período de julho a setembro de 2007.

As sementes foram tratadas com água a $100^{\circ} \mathrm{C}$, por 5 minutos, para quebra de dormência tegumentar (SCALON et al., 2004). Em seguida, as sementes foram separadas em dois lotes, e o primeiro foi caracterizado pela imersão das sementes em solução de espermidina 100 ppm durante 3 horas e, em seguida, nas soluções salinas, conforme descrito abaixo e sendo denominado CE (adaptado de FONSECA; PEREZ, 2001). No segundo lote, denominado SE (sem espermidina), as sementes foram imersas apenas nas soluções salinas. Posteriormente, todas as sementes foram desinfestadas com hiplocorito de sódio (1\%) durante 5 minutos e lavadas em água corrente. Em seguida, foram colocadas em placas de Petri previamente autoclavadas, contendo papel de filtro umedecido com $10 \mathrm{~mL}$ de soluções salinas de $\mathrm{KCl}, \mathrm{NaCl}$ e $\mathrm{CaCl}_{2}$ nos potenciais osmóticos de 0,0 (testemunha); -0,4; -0,8; -1,2; -1,6; -2,0 MPa para cada sal utilizado. As placas de Petri do tratamento controle foram umedecidas com água desionizada. As soluções salinas foram preparadas a partir da equação de Van’t Hoff (apud SALISBURY; ROSS, 1992). As placas de Petri foram seladas com filme plástico e colocadas para germinar em câmaras de germinação (BOD) equipada com quatro lâmpadas fluorescentes e iluminação contínua e com temperatura regulada para $15,20,30$ e $35^{\circ} \mathrm{C}$ a fim de se determinar o limite máximo de tolerância das sementes para cada sal em cada temperatura. Adotou-se, como critério de limite máximo de tolerância ao sal, o intervalo entre menor potencial osmótico, onde ocorreu germinação, e potencial subseqüente, onde as sementes não germinaram ou apresentaram-se deterioradas. As soluções testes foram trocadas semanalmente.

As avaliações da porcentagem e do índice de velocidade de germinação foram realizadas segundo Nakagawa (1999) em dias alternados, sendo consideradas germinadas as sementes que apresentaram extensão da raiz primária igual ou maior a $2 \mathrm{~mm}$, e foram finalizadas quando as leituras repetiram-se por três avaliações consecutivas.
Para cada sal, o delineamento experimental adotado foi o inteiramente casualizado em esquema fatorial 2 (com e sem espermidina) x 6 (potenciais osmóticos) x 3 (temperaturas de incubação) com três repetições de 20 sementes. Aos 25 dias após a semeadura, foram avaliadas relação raiz /parte aérea, massa fresca e massa seca das plântulas.

Os dados foram analisados pelo teste $\mathrm{F}$ e, havendo significância, as médias foram comparadas pelo teste de Tukey, a $5 \%$ de probabilidade , para comparar o efeito da temperatura e regressão para avaliar o efeito dos potenciais osmóticos (BANZATO; KRONKA, 2006).

\section{RESULTADOS E DISCUSSÃO}

Para todos os tratamentos, observou-se que a porcentagem de germinação foi reduzida com a diminuição dois potenciais osmóticos, com exceção da temperatura de $30{ }^{\circ} \mathrm{C}$ nos sais $\mathrm{KCl}$ e $\mathrm{NaCl}$ (Figura 1 ).

Para os três sais avaliados, a temperatura na qual ocorreu maior germinação das sementes foi a de $30{ }^{\circ} \mathrm{C}$ (Figura 1), sendo significativamente maior que as demais, porém, independente do sal utilizado, os limites de tolerância não foram alcançados. No entanto, as sementes tratadas com $\mathrm{KCl}$ e $\mathrm{NaCl}$ e incubadas a $30{ }^{\circ} \mathrm{C}$ apresentaram valores de porcentagem de germinação estáveis em todos os potenciais testados e significativamente maiores que nas demais temperaturas. Nas sementes tratadas com $\mathrm{CaCl}_{2}$, temperatura de $30{ }^{\circ} \mathrm{C}$ apresentou valores para porcentagem de germinação maiores em relação às demais nesse mesmo sal, porém diferiu entre os potenciais osmóticos testados, reduzindo-se significativamente no potencial de -2,0 MPa quando comparado ao potencial controle (Figura 1c).

Fonseca e Perez (1999), estudando a germinação de Anadenanthera pavonina L. (olho- de-dragão) tratada com os mesmos potenciais osmóticos dos mesmos sais, também observaram melhor porcentagem de germinação na temperatura de $30^{\circ} \mathrm{C}$.

As temperaturas de 15 e $20^{\circ} \mathrm{C}$ estão abaixo da temperatura ótima observada para sementes de mutambo $\left(30^{\circ} \mathrm{C}\right.$ ) (ARAÚJO-NETO;AGUIAR, 1999). Com o aumento da salinidade, as temperaturas de 20 e $35^{\circ} \mathrm{C}$ foram as que mais afetaram a porcentagem de germinação. Nas sementes mantidas a $35^{\circ} \mathrm{C}$, foi observada intensa proliferação de microorganismos, ocasionada pela umidade e temperatura elevada, além da redução no 

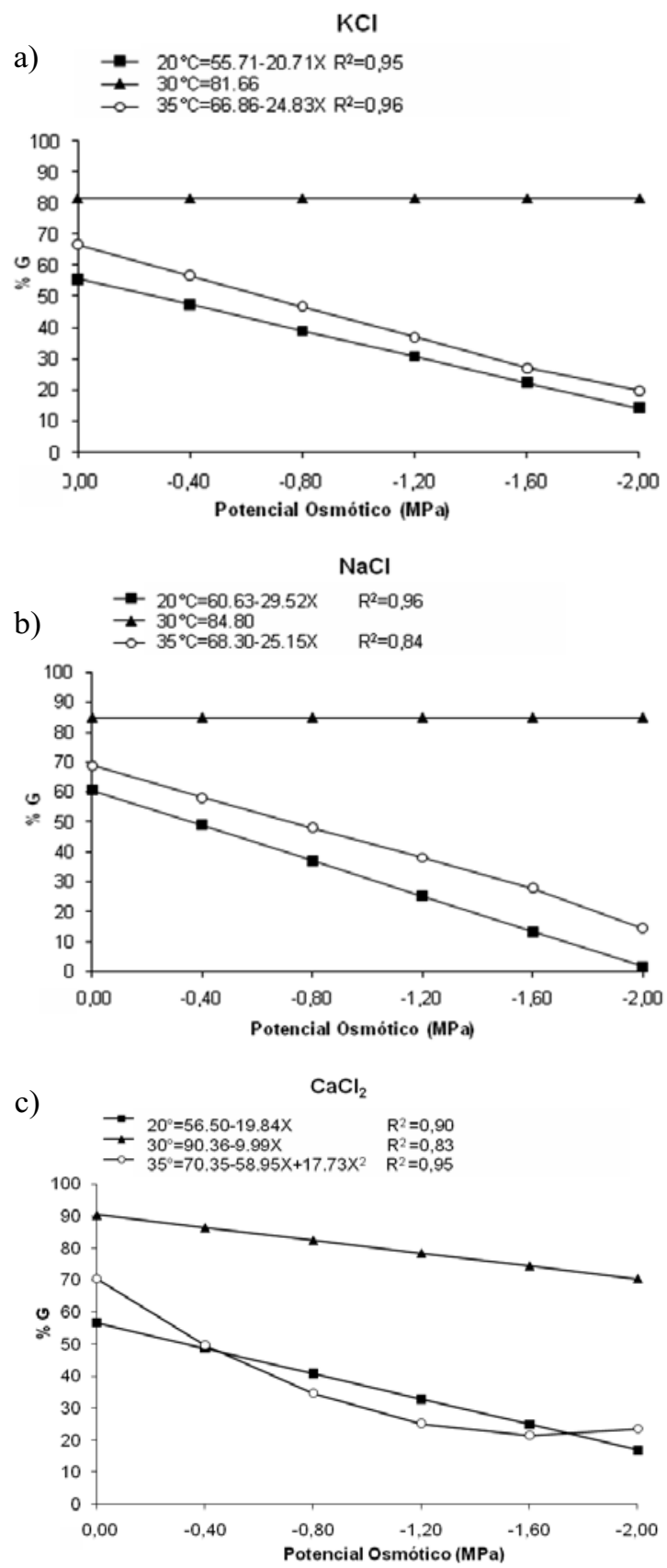

Figura 1 - Porcentagem de germinação de sementes de mutambo (Guazuma ulmifoliaLam) em diferentes temperaturas e potenciais osmóticos de $\mathrm{KCl}$ (a), $\mathrm{NaCl}$ (b) e $\mathrm{CaCl}_{2}$ (c). Dourados-MS, 2008.

Figure 1 - Germination percentage of Guazuma ulmifolia seeds at different temperatures and osmotic potentials of $\mathrm{KCl}(\mathrm{a}), \mathrm{NaCl}(\mathrm{b})$ and $\mathrm{CaCl} 2$ (c). Dourados, 2008. vigor. Araújo-Neto et al. (2002) observaram, também para mutambo, que nessa temperatura ocorreu alta porcentagem de germinação, porém menor velocidade de germinação e vigor das sementes. Entretanto, apesar de as sementes incubadas a $20^{\circ} \mathrm{C}$ não terem sofrido com a ação desses fatores, foi essa temperatura que apresentou menor porcentagem de germinação em todos os sais utilizados (Figura 1).

Ribeiro e Pelacani (2006) sugerem que a redução na porcentagem de germinação e o atraso no início da germinação com o aumento do estresse podem estar relacionados com a seca fisiológica produzida, pois, quando há aumento das concentrações de substâncias no meio germinativo, há diminuição do potencial osmótico e, consequentemente, redução do potencial hídrico. Esta redução pode afetar a cinética de absorção de água pelas sementes (efeito osmótico), como também elevar a níveis tóxicos a concentração de íons no embrião (efeito tóxico).

O potencial osmótico de soluções salinas pode apresentar valores mais negativos do que aquele apresentado pelas células do embrião, dificultando, portanto, a absorção da água necessária para a germinação. A diminuição da porcentagem e da velocidade de germinação de sementes submetidas ao estresse hídrico, ocasionado pelo aumento da salinidade, é atribuída à redução das atividades enzimáticas (SANTOS et al., 1992), indicando um efeito tóxico no embrião (CAMPOS; ASSUNÇÃO, 1990). Em geral, as espécies, tolerantes ou não, respondem de maneira semelhante ao estresse salino, ou seja, a porcentagem e a velocidade de germinação são inversamente proporcionais ao aumento da salinidade, variando apenas o limite máximo de tolerância ao sal (PEREZ; MORAES, 1994), conforme observado para as sementes de mutambo neste trabalho.

Segundo Vidaver e Hsiao (1975), as altas temperaturas podem levar à perda de viabilidade das sementes. Mayer e Poljakoff-Mayber (1989) afirmam que quanto maior a temperatura maior é o índice de velocidade de germinação, e acrescentam que quanto menor a temperatura maior é o tempo necessário para que todas as sementes germinem, e menor é a porcentagem total de germinação e a velocidade de germinação. Nos limites letais, são verificadas mudanças na permeabilidade das membranas, seguidas por desnaturação das proteínas das sementes e perda de material.

Revista Árvore, Viçosa-MG, v.35, n.3, Edição Especial, p.605-616, 2011 
Araújo-Neto et al. (2002) consideram a faixa de 25 a $35^{\circ} \mathrm{C}$ de temperatura ótima para $\mathrm{G}$ ulmifolia, e a temperatura máxima até $40^{\circ} \mathrm{C}$, semelhante ao obtido neste estudo, na qual a germinação ocorreu em maior porcentagem na temperatura de $30^{\circ} \mathrm{C}$, alcançando médias de 81,66 e 84,80\% quando tratadas com os sais $\mathrm{KCl}$ e $\mathrm{NaCl}$, respectivamente. Lima et al. (2006) observaram que, para Caesalpinia ferrea Mart. a temperatura de $30^{\circ} \mathrm{C}$ também promoveu o menor tempo médio de germinação. Os resultados quanto à melhor temperatura para germinação estão de acordo com o proposto por Borges e Rena (1993), pois sementes de grande número de espécies florestais subtropicais e tropicais mostram-se com potencial máximo de germinação na faixa de temperatura entre 20 e $30{ }^{\circ} \mathrm{C}$.

A análise dos resultados apresentados na Figura 2 permitiu concluir que, apesar de não haver diferença significativa entre as temperaturas e os potenciais osmóticos dos sais $\mathrm{KCl}$ e $\mathrm{CaCl}_{2}$ (Figura 2a e 2b), o decréscimo nos potenciais osmóticos induzidos pelas soluções salinas reduziu o índice de velocidade de germinação das sementes. Sousa et al. (2008) observaram o mesmo avaliando o estresse hídrico e salino na germinação de Plantago ovata Forsk.

Não foi observada interação significativa entre as temperaturas e a presença ou ausência de espermidina para o sal KCl, por isso os dados não foram apresentados. Independente de o sal utilizado ser o $\mathrm{NaCl}$ ou $\mathrm{CaCl}_{2}$ (Figuras 3a e 3b), as sementes tiveram a sua velocidade de germinação diminuída nas temperaturas de 20 e $35{ }^{\circ} \mathrm{C}$ quando comparadas aos valores de índice de velocidade de germinação na temperatura de $30{ }^{\circ} \mathrm{C}$, da mesma forma como foi observado para porcentagem de germinação. Resultados semelhantes foram observados independentes da presença ou ausência de espermidina. Embora a interação entre temperatura e espermidina tenha ocorrido somente para os sais $\mathrm{NaCl}$ e $\mathrm{CaCl}_{2}$ a diferença entre os tratamentos CE e SE só foi significativa para sementes tratadas com $\mathrm{CaCl}_{2}$ nas temperaturas de 20 e $35^{\circ} \mathrm{C}$ (Figura 3a). Na temperatura de $20^{\circ} \mathrm{C}$, o índice de velocidade de germinação das sementes do lote SE foi melhor quando comparado ao lote CE. No entanto, na temperatura de $35^{\circ} \mathrm{C}$, os índices de velocidade de germinação foram maiores para as sementes do lote CE. Portanto, o tratamento das sementes CE na temperatura de $35{ }^{\circ} \mathrm{C}$ mostrou-se eficaz na atenuação dos efeitos da salinidade induzida pelos $\mathrm{CaCl}_{2}$, melhorando os resultados para o índice de velocidade de germinação quando comparado com o das sementes do lote SE. a)

$\mathrm{KCl}$

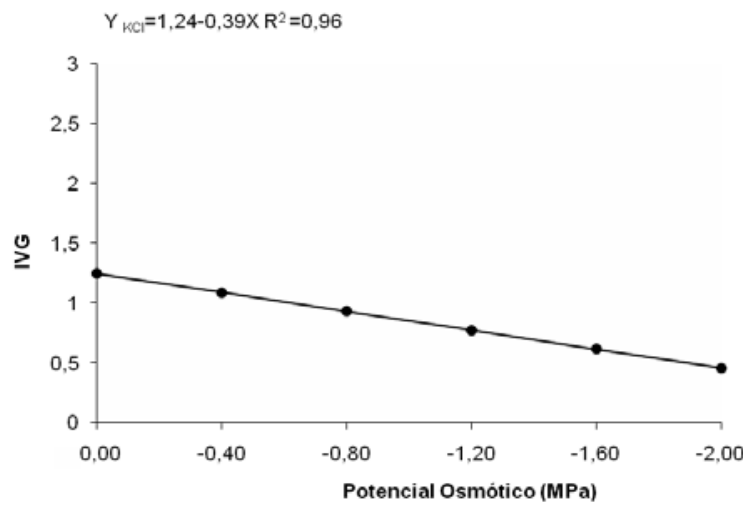

b)

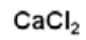

$$
\mathrm{Y}_{\mathrm{CaCl}}=1,33-0,82 \mathrm{X}+0,170 \mathrm{X}^{2} \quad \mathrm{R}^{2}=0,97
$$

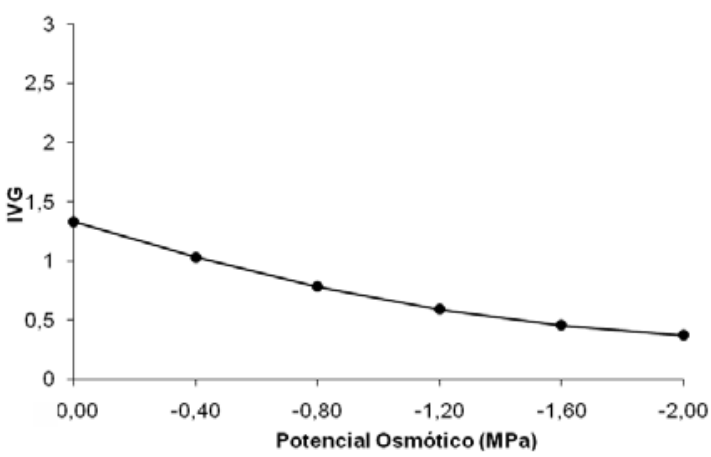

c)

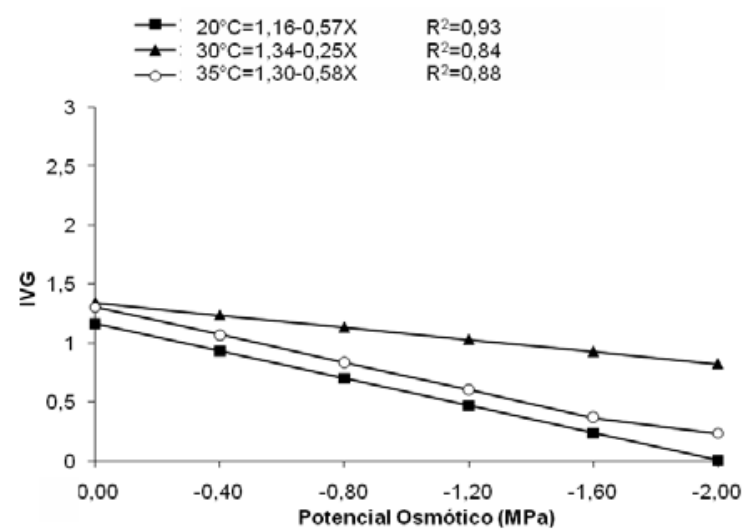

Figura 2 - Índice de velocidade de germinação de sementes de mutambo (Guazuma ulmifolia Lam.) em diferentes potenciais osmóticos dos sais $\mathrm{KCl}(\mathrm{a})$, $\mathrm{CaCl}_{2}$ (b), e $\mathrm{NaCl}$ (c). Dourados-MS, 2008.

Figure 2-Germination speed index of Guazuma ulmifolia seeds in different osmotic potentials of $\mathrm{KCl}(a)$, CaCl2 (b), and $\mathrm{NaCl}$ (c). Dourados, 2008. 
Para as sementes tratadas em solução de $\mathrm{NaCl}$, apesar de também ser observado decréscimo com a redução dos potenciais, houve interação entre temperaturas e potenciais osmóticos, nas quais o maior índice de velocidade de germinação ocorreu na temperatura de $30^{\circ} \mathrm{C}$ (Figura 3b). Os índice de velocidade de germinação de sementes tratadas com $\mathrm{NaCl}$, da mesma forma que a porcentagem de germinação, foram mais afetados a $20^{\circ} \mathrm{C}$, apresentando velocidade zero no potencial mais negativo.

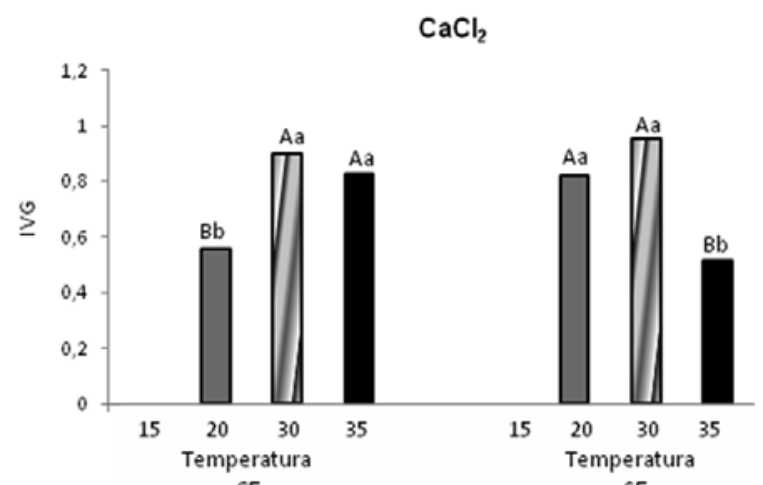

CE

SE

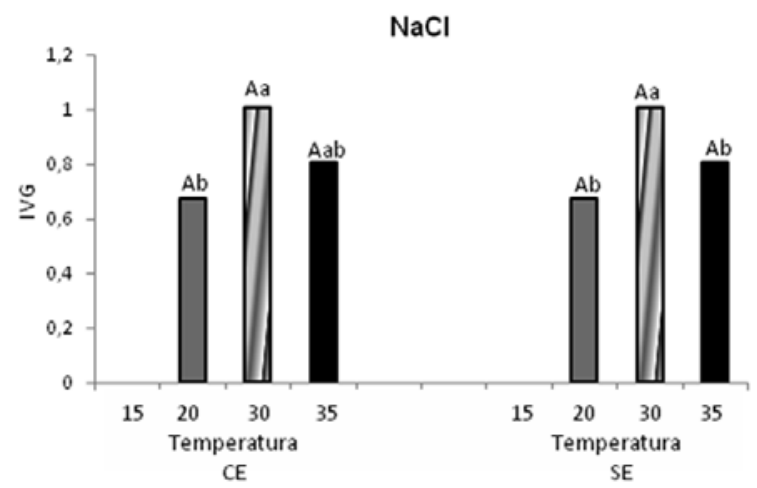

Figura 3 - Índice de velocidade de germinação de sementes de mutambo (Guazuma ulmifolia Lam.) embebidas em diferentes soluções salinas tratadas com (CE) e sem espermidina (SE. Médias seguidas de letras minúsculas comparam as temperaturas dentro do fator espermidina e médias seguidas de letras maiúsculas comparam a espermidina dentro do fator temperatura. Dourados-MS, 2008.

Figure 3-Germination speed index of Guazuma ulmifolia absorved in different treated saline solutions with (CE) and without spermidine (SE). Means followed by lower case letters compare the temperatures of the spermidine factor and means followed by capital letters compare the spermidine of the factor temperature. Dourados, 2008.
Em sementes tratadas com $\mathrm{NaCl}$ a germinação ocorreu até o potencial de-2,0 MPa, no entanto, nessa concentração, a germinação foi nula a $20^{\circ} \mathrm{C}$. Isso pode evidenciar que essas condições não adequadas para germinação podem induzir as sementes a estado de dormência secundária ou mesmo causar efeito tóxico resultante da concentração de íons no protoplasma (FANTI; PEREZ, 2004).

Ribeiro e Pelacani (2006), por sua vez, observaram o mesmo resultado analisando a germinação de Anadenanthera colubrina (Vell.) Brenan em presença de $\mathrm{NaCl}$. No entanto em sementes de A. pavonina, o cloreto de potássio apresentou-se como o agente osmótico mais tóxico, seguido pelos cloretos de sódio e cálcio, sendo que a germinação foi observada até o potencial de -1,4 MPa; a partir de -1,5 MPa não foi computado mais nenhum evento de germinação.

O uso de temperaturas altas na germinação de sementes tem ocasionado estresse, proporcionando-lhes dormência térmica ou mesmo perda de viabilidade (VIDAVER; HSIAO, 1975; BEWLEY; BLACK, 1982). Carvalho e Nakagawa (1988) afirmam que temperaturas inferiores ou superiores à ótima tendem a reduzir a velocidade da germinação, expondo as sementes por maior período a fatores adversos, o que pode levar à redução no total de germinação. No entanto, de acordo com Labouriau e Agudo (1987), esse atraso na germinação pode aumentar a probabilidade das plântulas encontrarem condições favoráveis em ambiente mutável.

Não foi observada interação significativa entre as concentrações salinas e os demais tratamentos para a relação raiz/parte. Essa relação foi significativamente maior na temperatura de $20^{\circ} \mathrm{C}$, independente do sal utilizado, e o sistema radicular foi maior em comparação com a parte aérea, sendo menor na temperatura de $35^{\circ} \mathrm{C}$, com excessão do $\mathrm{CaCl}_{2}$ (Figura 4c). Não foram observadas diferenças significativas com e sem espermidina para $\mathrm{KCl}$ e $\mathrm{NaCl}$ (Figura 4a e 4b).

A efetividade das poliaminas em proteger as membranas corresponde ao número de cargas por molécula, da concentração e do tipo de poliamina exógena utilizada no tratamento, além de necessitar das condições favoráveis para que isso ocorra(GALSTON; KAUR-SAWHNEY, 1987; BOUCHEREAU et al., 1999). Provavelmente, a temperatura de $20^{\circ} \mathrm{C}$, considerada abaixo da ótima, não tenha propiciado a espermidina a desempenhar seu efeito protetor durante o crescimento da plântula. 


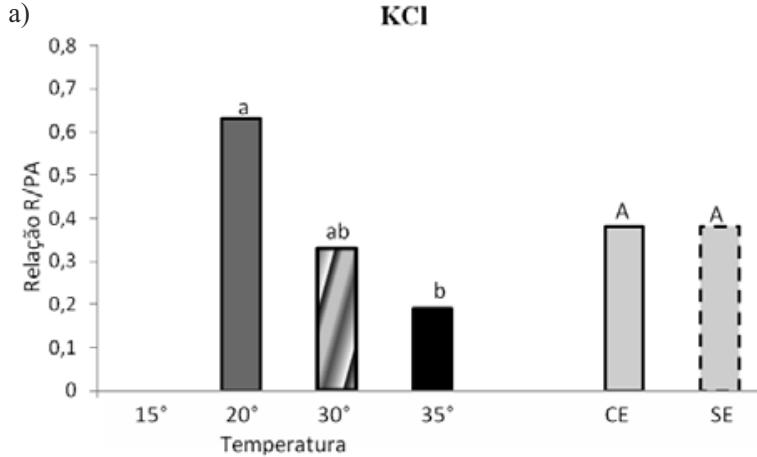

b)

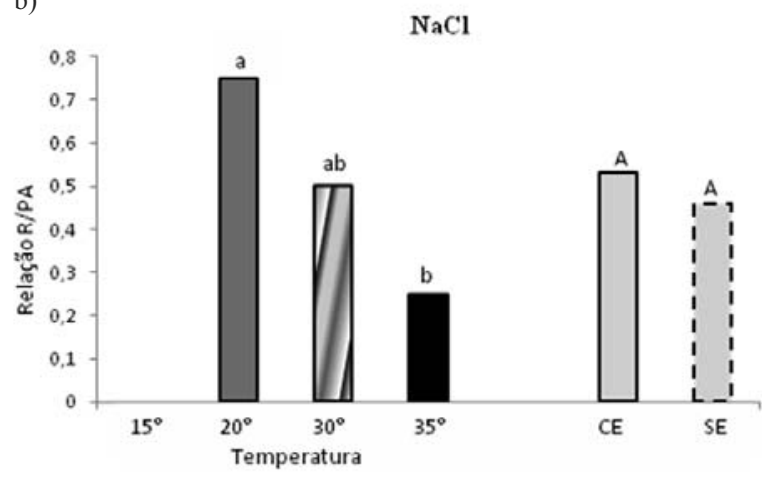

c)

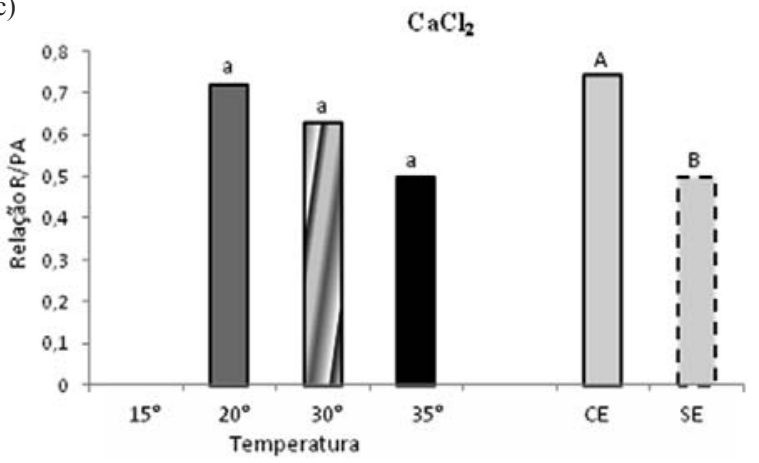

Figura 4 - Relação Raiz/Parte Aéra de plântulas de mutambo (Guazuma ulmifoliaLam.) embebidas em diferentes soluções salinas tratadas com (CE) e sem espermidina (SE). Médias seguidas de letras minúsculas comparam a temperatura, médias seguidas de letra maiúscula comparam com (CE) e sem espermidina (SE). Dourados-MS, 2008.

Figure 4-Relation Root/Aerial Part of Guazuma ulmifolia seedlings absorbed in different treated saline solutions with (CE) and without spermidine (SE). Means followed by lower case letters compare the temperatures of the spermidine factor and means followed by capital letters compare the spermidine of the factor temperature. Dourados, 2008.
Para sementes tratadas com $\mathrm{CaCl}_{2}$ não houve diferenças significativas entre as temperaturas avaliadas, no entanto, no tratamento CE, a relação raiz/parte aérea foi significativamente maior do que o SE, e a parte aérea foi menos estimulada que a raiz (Figura 4c).

O aumento da concentração de sais no meio radicular provoca redução no potencial hídrico das raízes. De acordo com Larcher (2000), a primeira e mais sensível resposta à deficiência hídrica é a diminuição da turgescência e, associada a esse evento, a diminuição do processo de crescimento (particularmente o crescimento em extensão). Dessa forma, o desenvolvimento do sistema radicular das plantas é reduzido com déficit hídrico.

Em relação ao sal utilizado, a adição de $\mathrm{KCl}$ na solução nutritiva reduziu significativamente a razão raiz /parte aérea das plântulas incubadas a 30 e $35^{\circ} \mathrm{C}$ (Figura 5), indicando que, para esse sal, o efeito da salinidade foi mais evidente na raízes que na parte aérea, uma vez que houve menor crescimento das raízes. O sal que apresentou maior relação raiz/parte aérea independente da temperatura foi o $\mathrm{CaCl}_{2}$, que mostrou-se menos inibitório do crescimento das raízes.

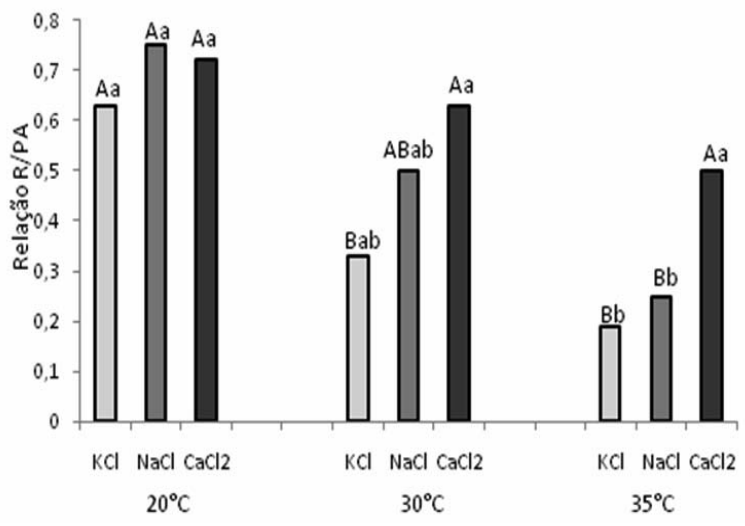

Figura 5 - Relação Raiz/Parte Aérea das plântulas de mutambo (Guazuma ulmifolia Lam. ) tratadas com soluções salinas e temperaturas diferentes. Médias seguidas de letras minúsculas comparam os sais dentro do fator temperatura, médias seguidas de letras maiúsculas comparam a temperatura dentro de cada fator sal. Dourados-MS, 2008.

Figure 5 - Relation Root/Aerial Part of Guazuma ulmifolia seedlings treated with saline solutions and different temperatures. Means followed by lower case letters compare the temperatures of the spermidine factor and means followed by capital letters compare the spermidine of the factor temperature of each salt. Dourados, 2008. 
Em termos relativos, verifica-se que a redução foi maior na temperatura de 35 e $30^{\circ} \mathrm{C}$ do que na de $20^{\circ} \mathrm{C}$, sugerindo, então, que a parte aérea das plântulas incubadas a $35^{\circ} \mathrm{C}$ foram menos afetadas pela salinidade. A salinidade diminuiu o potencial hídrico do solo, e o estresse osmótico dificultou a embebição de água e a absorção de nutrientes pelas plantas. O desequilíbrio iônico e os efeitos tóxicos dos íons, por exemplo o $\mathrm{Na}^{+}$, prejudica a germinação, nutrição e o metabolismo vegetal. Entretanto, plântulas são mais intolerantes à salinidade em relação às plantas adultas, e a salinidade próxima à superfície do solo é mais prejudicial ao desenvolvimento das plântulas em relação à salinidade em solos profundos (ou em profundidade), o que prejudica a revegetação de locais salinos ou alcalinos, devido à dificuldade do estabelecimento das plântulas (HANSLIN; EGGEN, 2005). Outra explicação aceitas para a inibição do crescimento pelo sal é o desvio de energia do crescimento para a manutenção (RICHARDSON; McCREE, 1985).

Segundo Goss (1973), a relação raiz/parte aérea é uma correlação de desenvolvimento, expressando o fato de que o crescimento radicular pode afetar o da parte aérea, e vice-versa. Com estresse hídrico, geralmente aumenta a relação entre matéria seca da raiz e matéria seca da parte aérea.

Na temperatura de $20{ }^{\circ} \mathrm{C}$, elas tenderam a desenvolver mais o sistema radicular, e na temperatura de $35^{\circ} \mathrm{C}$ a parte aérea foi maior do que a raiz, por isso a relação raiz/parte aérea foi a mais baixa. Isso pode ser explicado pela umidade e pela intensa proliferação de microorganismos ocasionados nessa temperatura, o que causou deterioração do sistema radicular da maioria das plântulas.

Assim como para a germinação, a temperatura de $30{ }^{\circ} \mathrm{C}$ foi a temperatura ideal para o desenvolvimento das plântulas de Guazuma ulmifolia, ou seja, nessa temperatura, as plântulas apresentaram desenvolvimento médio entre parte aérea e sistema radicular, porém maior acúmulo de massa seca. As plântulas obtidas na temperatura de $35^{\circ} \mathrm{C}$ apresentaram-se menos vigorosas em relação às plântulas obtidas nas demais temperaturas. Isso ocorreu devido ao estresse térmico causado pela temperatura elevada, bem como à proliferação de microorganismos ocasionada nessa condição.

Na temperatura extrema de $35^{\circ} \mathrm{C}$, as plântulas de Guazuma ulmifolia submetidas à solução de $\mathrm{CaCl}_{2}$ mantiveram o alto desempenho do sistema radicular em relação às plântulas submetidas aos demais tratamentos com soluções salinas. Possivelmente, o $\mathrm{Ca}^{+2}$ presente na solução suavizou o efeito tóxico do sal no desenvolvimento das raízes de Guazuma ulmifolia. Tobe et al. (2003) observaram que o $\mathrm{NaCl}, \mathrm{KCl}$ e $\mathrm{MgCl}_{2}$ foram tóxicos para as raízes de Artemísia ordosica, Aristida adscensioris e Bassia dasyphylla, espécies do deserto chinês. Porém, o efeito tóxico dos sais foi amenizado pela adição de baixas concentrações de $\mathrm{CaCl}_{2}$. Resultados semelhantes aos observados para Guazuma ulmifolia também foram observados por Nobre et al. (2003) em mudas de gravioleira e por Hackbart e Cordazzo (2007) em plântulas de Hydrocotyle bonariensis Lam. (acariçoba).

Resultados contraditórios são encontrados por diversos autores trabalhando com espécies diferentes. Dessa forma, alguns relatam maior sensibilidade da parte aérea em condições de salinidade: gravioleira (NOBRE et al., 2003), algodoeiro (MELONI et al., 2001) e salvadora (RAMOLIYA; PANDEY, 2002), em contrapartida outros autores indicam o sistema radicular ser mais sensível à salinidade: abacaxizeiro (MARINHO et al., 1998) e alho (AMORIM et al., 2002) possivelmente devido à constituição genética.

Apesar de geralmente o efeito salino ser negativo, há plantas classificadas como halófitas ou natrofílicas, para as quais o elemento sódio é benéfico com estímulo ao crescimento (MARSCHNER, 1995 apud SILVA et al., 2000). Bergmann (1992) afirma que tais plantas têm a capacidade de estabelecer equilíbrio osmótico com o baixo potencial de água no solo. Isso é possível por acumularem os íons absorvidos no vacúolo das células foliares, mantendo a concentração salina no citoplasma e nas organelas em baixos níveis, de modo a não interferirem nos mecanismos enzimáticos e metabólicos e na hidratação de proteínas das células.

Avaliando a massa fresca das plântulas, observa-se que a temperatura de $30{ }^{\circ} \mathrm{C}$ apresenta-se como a melhor temperatura para todos os sais, com médias de 41,8 mg e 46,9 mg de massa fresca para $\mathrm{NaCl}$ e $\mathrm{CaCl}_{2}$, respectivamente (Figura 6 ).

Não foi observada interação significativa das concentrações salinas para a massa seca das plântulas. Na interação entre temperatura e espermidina, houve diferença significativa apenas para o $\mathrm{CaCl}_{2}$, e os valores de massa seca foram maiores a $30^{\circ} \mathrm{C}$ no lote $\mathrm{CE}$, embora no lote $\mathrm{SE} 20$ e $30^{\circ} \mathrm{C}$ não tenha variado significativamente 

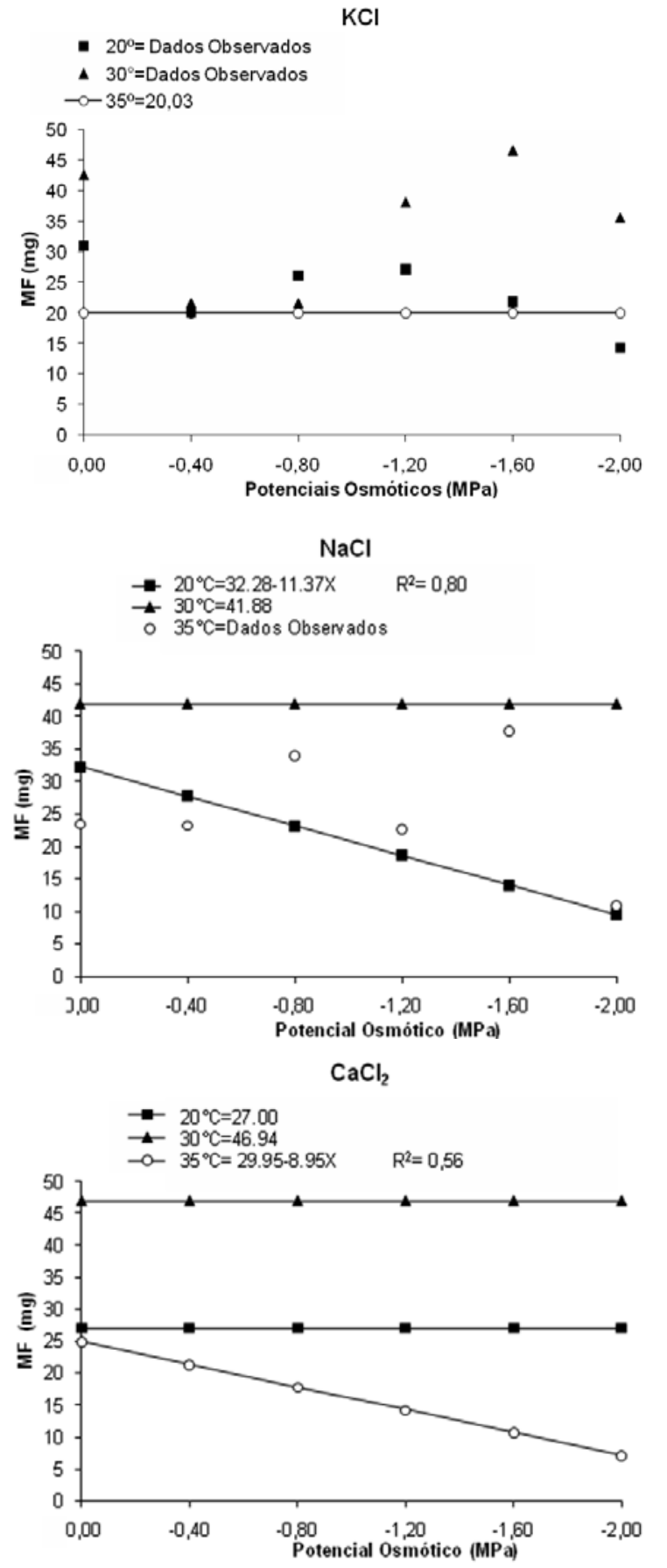

Figura 6 - Massa Fresca de plântulas de mutambo (Guazuma ulmifolia Lam.) em diferentes temperaturas e potenciais osmóticos. Dourados-MS, 2008.

Figure 6 - Fresh mass of Guazuma ulmifolia seedlings in different temperatures and osmotic potentials. Dourados, 2008.
(Figura 7). No entanto, para a interação entre sal e potencial osmótico das soluções salinas não houve interação significativa para a característica massa seca de plântulas. Desse modo, a massa seca das plântulas não foi influenciada pelos diferentes níveis de salinidade, ficando praticamente constantes.

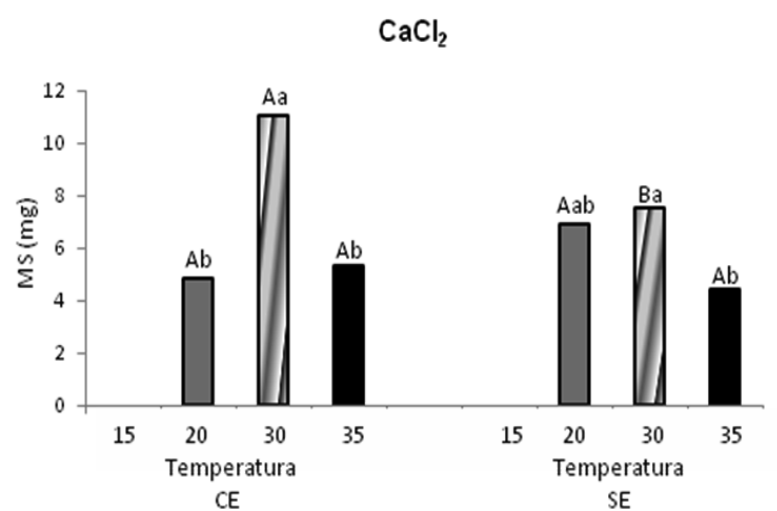

Figura 7 - Massa seca de plântulas de mutambo (Guazuma ulmifolia Lam. ) embebidas em soluções salinas $\mathrm{CaCl}_{2}$ tratadas com (CE) e sem espermidina (SE) a $15,20,30$ e $35^{\circ} \mathrm{C}$. Médias seguidas de letras minúsculas comparam as temperaturas testadas dentro do fator espermidina, e médias seguidas de letras maiúsculas comparam o tratamento com e sem espermidina dentro do fator temperatura. Dourados-MS, 2008.

Figure 7 - Dry mass of Guazuma ulmifolia seedlings absorbed in treated saline solutions with (CE) and without spermidine (SE). Means followed by lower case letters compare the temperatures of the spermidine factor and means followed by capital letters compare the spermidine of the factor temperature. Dourados, 2008.

Normalmente, em plantas sensíveis, a salinidade diminui a taxa de emergência e reduz a matéria seca e fresca da parte aérea e do sistema radical (SHANNON et al., 1998). No entanto, apesar de não ter determinado os limites de tolerância de G. ulmifolia à salinidade, esta pode ser uma espécie tolerante também à salinidade nos potenciais osmóticos avaliados neste estudo, reforçando informações de Rosado (2008) de que ela é uma espécie pioneira e rústica em áreas de revegetação.

Neste contexto, Perez (1988 apud NASSIF; PEREZ,1997) verificaram que sementes de Prosopis juliflora mostrou-se tolerante ao $\mathrm{NaCl}, \mathrm{CaCl}_{2}$ e $\mathrm{KCl}$ (JELER; PEREZ, 1997). 
Considerando a utilização de espécies nativas para a recuperação de áreas degradadas, a espécie mutambo, sendo uma planta rústica, pode ser utilizada em regiões inóspitas, como em locais com solos salinos, como foi demonstrado com os resultados desta pesquisa.

\section{CONCLUSÕES}

Nas condições controladas deste estudo, Guazuma ulmifolia apresenta germinação e crescimento de plântula em ambiente com salinidade de -2,0MPa e temperatura em torno de $30^{\circ} \mathrm{C}$, não apresentando limite de tolerância até essa concentração em nenhum dos sais avaliados.

\section{REFERÊNCIAS}

AMORIM, J. R. A. et al Efeito da salinidade e modo de aplicação da água de irrigação no crescimento e produção de alho. Pesquisa Agropecuária Brasileira, v.37, n.2, p.167176, 2002.

ARAÚJO-NETO, J. C. et al. Temperaturas Cardeais e efeito da luz na germinação de sementes de mutamba. Revista Brasileira de Engenharia Agrícola e Ambiental, v.6, n.3, p.460-465, 2002.

ARAÚJO-NETO, J. C.; AGUIAR, I. B. Desarrollo ontogénico de plántulas de Guazuma ulmifolia (Sterculiaceae). Revista de Biologia Tropical, v.47, n.4, p.785-790, 1999.

BANZATTO, D.A.; KRONKA, S.N. Experimentação agrícola. 4. ed. Jaboticabal: FUNEP/UNESP, 2006. 237p.

BERGMANN, W. Nutritional disorders of plants: development, visual and analyticaldiagnosis. New York: G. Fisher, 1992. 741p.

BEWLEY, J. D.; BLACK, M. Physiology and biochemistry of seed and relation to germination: viability, dormancy and environmental control. Berlin: Springer Verlag 1982. 375p.

BORGES, E. E. L.; RENA, A. B. Germinação de sementes. In: AGUIAR, I.B.; PIÑA-RODRIGUES, F. C. M.; FIGLIOLIA, M. B. (Coords.) Sementes florestais tropicais. Brasília: ABRATES, 1993. p.83-136.
BOUCHEREAU, A. et al. Polyamines and environmental challenges: recent development. Plant Physiology, v.140, p.103-125, 1999.

CAMPOS, I. S.; ASSUNÇÃO, M. V. Estresse salino e hídrico na germinação e vigor do arroz. Pesquisa Agropecuária Brasileira, v.25, n.6, p.857-862, 1990.

CARVALHO, N. M.; NAKAGAWA, J. Sementes: ciência, tecnologia e produção. 3.ed. Campinas: Fundação Cargill, 1988. 424p.

FANTI, S. C.; PEREZ, S. C. J. G. A. Germinação de sementes de paineira sob estresses hídrico e salino. Pesquisa Agropecuária

Brasileira, v.39, n.9, p.903-909, 2004.

FERRETTI, A. R. et al. Classificação das espécies arbóreas em grupos ecológicos para revegetação com nativas no Estado de São Paulo. Florestar Estatístico, v.3, n.7, p.73-77, 1995.

FONSECA, S. C. L.; PEREZ, S. C. J. G. A. 0Germinação de sementes de olho de dragão (Anadenanthera pavonina L.) ação de poliaminas na atenuação do estresse salino. Revista Brasileira de Sementes, v.23, n.2, p.14-20, 2001.

FONSECA, S. C. L; PEREZ, S. C. J. G. A. Efeito dos sais e da temperatura na germinação de sementes de olho de dragão (Anadenanthera pavonina L.-Fabaceae). Revista Brasileira de Sementes, v.21, n.2, p.70-77, 1999.

FREIRE, A. L. O. Fixação do nitrogênio, crescimento e nutrição mineral de leucena sob condições de salinidade. 2000. 92f. Tese (Doutorado em Agronomia) - Universidade Estadual Paulista, Jaboticabal, 2000.

GALSTON, A. W.; KAUR-SAWHNEY, R. Polyamines and senescence in plants. In: THOMPSON, W., NOTHANGEL, E.; HUFFAKER, R. (Eds.). Plant senescence: Its biochemistry and physiology. Rockville: America Society of Plant Physiology, 1987. p.176-81.

GOSS, J. A. Physiology of plants end their cells. New York: Pergamon, 1973. 457p. 
HACKBART, V. C. S.; CORDAZZO, C. V. Germinação e crescimento de plântulas de Hydrocotyle bonariensis Lam. (Apiaceae) em diferentes concentrações de $\mathrm{NaCl}$. Atlântica, v.29, n.2, p.85-92, 2007

HASLIN, H. M.; EGGER, T. Salinity tolerance during germination of seashore halophytes and salt-tolerant grass cultivars. Seed Science Research, v.15, n.1, p.43-45, 2005.

JELLER, H.; PEREZ, S. C. J. G. A. Efeito da salinidade e da semeadura em diferentes profundidades na viabilidade e no vigor de Copaifera langsdorffii Desf. Revista Brasileira Sementes, v.19, n.2, p.219-225, 1997.

KAGEYAMA, P. Y.; GANDARA, F. B.; OLIVEIRA, R. E. Biodiversidade e restauração da floresta tropical. In: KAGEYAMA, P. Y. et al. (Orgs.). Restauração ecológica em ecossistemas naturais. Botucatu: FEPAF, 2003. 340p.

KOETJE, D. S.; KONONOWICZ, H.; HODGES, T. K. Polyamine metabolism associated with growth and embryogenic potencial of rice. Journal of Plant Physiology, v.141, p.215-220, 1993.

LABOURIAU, F. G. A.; AGUDO, M. On the physiology of germination in Salvia hispanica L. temperature effects. Anais da

Academia Brasileira de Ciências, v.59, p.57-69,1987.

LARCHER, W. Ecofisiologia vegetal. São Carlos: Rima, 2000. 529p.

LIMA, J. D. Efeito da temperatura e do substrato na germinação de sementes de Caesalpinia férrea Mart. ex Tul. (Leguminosae, Caesalpinoideae). Revista Árvore, v.30, n.4, p.513-518, 2006.

LORENZI, H. Árvores brasileiras: manual de identificação e cultivo de plantas arbóreas nativas do Brasil. Nova Odessa: Plantarum, 2002. v.1. p.343.

MAYER, A. C.; POLJAKOFF-MAYBER, A. The germination of seeds. London: Pergamon Press, 1989. 270p.
MARINHO, F. J. L.; FERNANDES, P. D.; GHEYI, H. R. Desenvolvimento de mudas de abacaxizeiro, cv. Smooth Cayenne, sob diferentes condições de salinidade da água de irrigação. Revista Brasileira de Engenharia Agrícola e Ambiental, v.2, n.1, p.1-5, 1998.

MELONI, D. A. et al. Contribution of proline and inorganic solutes to osmotic adjustment in cotton under salt stress. Journal of Plant Nutrition, v.24, n.3, p.599- 612, 2001.

NAKAGAWA, J. Testes de vigor baseados no desempenho das plântulas. In: KRZYZANOWSKI, F.C.; VIEIRA, R.D.; FRANÇA NETO, J.B. (Eds.).

Vigor de sementes: conceitos e testes. Londrina: ABRATES, 1999. p.2.1 - 2.24.

NASSIF, S. M. L.; PEREZ, S. C. J. G. A. Germinação de sementes de amendoim - do campo (Pterogyne nitens) influência dos tratamentos para superar a dormência e profundidade de semeadura. Revista Brasileira de Sementes, v.19, n.1, p.172179, 1997.

NOBRE, R. G. et al. Germinação e formação de mudas enxertadas de gravioleira sob estresse salino. Pesquisa Agropecuária Brasileira, v.38, n.12, p.1365-1371, 2003.

PEREZ, S. C. J. G. A.; MORAES, J. A. P. V. Estresse salino no processo germinativo de algarobeira e atenuação de seus efeitos pelo uso de reguladores de crescimento. Pesquisa Agropecuária Brasileira, v.29, n.3, p.389-396, 1994.

POPINIGS, F. Fisiologia de sementes. Brasília: Agriplan, 1985. 285p.

RAMOLIYA, P. J.; PANDEY, A. N. Effect of increasing salt concentration on emergence, growth and survival of seedlings of Salvadora oleoides. Journal of Arid

Environments, v.51, n.1, p.121-132, 2002.

RIBEIRO, R. C.; PELACANI, C. R. Influência do manitol e $\mathrm{NaCl}$ na germinação de sementes de duas espécies de leguminosas com importância no semi-árido baiano.

Sitientibus Série Ciências

Biológicas, v.6, n.2, p.105-109, 2006. 
RICHARDSON, N. S. G.; MCCREE, K. J. Carbon balance and water relations of sorghum exposed to salt and water stress. Plant Physiology, v.79, n.4, p.1015-20, 1985.

ROSADO, S. C. S. Revegetação de dunas degradadas no litoral norte da Paraíba. 2008. Disponível em $:<\underline{\text { http: } / /}$ www.cemac-ufla.com.br/trabalhospdf/Palestras/ Rosado.pdf>. Acesso em: 05/12/08.

SANTOS, V. L. M. et al. Efeito do estresse salino e hídrico na germinação e vigor de sementes de soja. Revista Brasileira de Sementes, v.14, n.2, p.189-194, 1992.

SALISBURY, F. B.; ROSS, C. W. Plant physiology. 4.ed. Belmont: Wadsworth Publishing Company, 1992. 682p.

SCALON, S. P. Q. et al. Tratamentos prégerminativos na germinação de sementes de Guazuma ulmifolia Lam. In: CONGRESSO

BRASILEIRO DE OLERICULTURA, 44., 2004, Campo Grande. Horticultura Brasileira, v.22. p.343, 2004.

SHANNON, M. C. et al. Assessment of salt tolerance in rice cultivars in response to salinity problems in Califórnia. Crop Science, v.38, n.2, p.394-398, 1998.
SILVA, C. R. et al. Prevenção de solos à salinização. (Pós-graduação em Irrigação e Drenagem) 2009. Disponível em: $<\underline{\text { http:// }}$ www.irrigarte.hpg.ig.com.br/Salinidade.htm> Acesso em: <19/01/2009>

SILVA, F. A. M. et al. Efeito do estresse salino sobre a nutrição mineral e o crescimento de mudas de aroeira (Myracrodruon urundeuva) cultivadas em solução nutritiva. Cerne, v.6, n.1, p.52-59, 2000.

SOUSA, M. P. et al. Estresses hídrico e salino no processo germinativo das sementes de Plantago ovata Forsk. (Plantaginaceae).

Revista Árvore, v. 32, n. 1. p.33-38, 2008.

VIDAVER, W., HSIAO, A. I. Secondary dormancy in light sensitive lettuce seeds incubated anaerobically or at elevated temperature. Canadian Journal of Botany, v.53, p.2557-2560, 1975.

TOBE, K., ZHANG, L.; OMASA, K. Alleviatory effects of calcium on the toxicity of sodium, potassium and magnesium chlorides to seed germination in three nonhalophytes. Seed Science Research, v.13, n.1, p.47-54, 2003. 